\title{
Synergistic Model Construction of Enterprise Financial Management Informatization
}

\author{
$\mathrm{Ji} \mathrm{Yu^{1 }}$ \\ ${ }^{1}$ School of accountancy, Shandong University of Finance and economics \\ Shandong, Ji'nan, China, 250000 \\ 1Jiyuasdf@163.com
}

Keywords: enterprise finance, synergistic model, construction, effect

\begin{abstract}
The thesis establishes three-dimensional synergistic governance model of enterprise group finance. With the theory of systematics, the construction is on the basis of three-dimensional synergistic frameworks called level dimension, content dimension and process dimension. Based on process dimension, we construct the framework of enterprise finical synergistic governance model, collaborating with three effects which are financial strategic synergy, financial resource synergy and financial interest synergy. Therefore, we analyze the elements of the three synergistic effects respectively, and the interaction as Ill as balance relationship among the three synergistic effects. Through the unascertained measurement theory, we build the unascertained evaluation model of enterprise group financial synergistic effects. Empirical analysis shows that the current overall level of enterprise group financial synergistic effects is relatively low. And among the three enterprise financial synergistic effects, enterprise strategic synergy is relatively strong, while financial interest synergy is kind of weak, and financial resource synergy is the worst.
\end{abstract}

\section{Introduction}

Financial management informatization is a management information system that aims to realize the coordination between finance and business on the basis of modern information technology, so as to adapt to e-commerce business model ${ }^{[1,2,3]}$. This kind of financial information management combines financial management method, concept and modern information technology. At the same time, it makes financial management system, financial accounting report system and accounting system as a whole, and ultimately achieves a high degree of integration of information flow, material flow, business flow and capital flow, as well as the sharing of information resources. By implementing informatization construction on financial management, the enterprises will achieve to process financial information remotely with the application of computer and network technology in financial management. It regards enterprise financial information as its object, which helps to form standardized management of finance gradually, thereby conducting comprehensive and timely information processing of enterprise control, decision-making, management, leadership and so on. At the present stage, however, with the innovation of existing financial management model, how can we find a better way for the transmission process and sharing mode of enterprise financial information? It has a great significance on not only the promotion of efficient management for enterprise financial information, but the increase of modern enterprise management level.

This thesis adopts literature research, questionnaire survey, empirical analysis, theoretical reasoning as well as other research methods, so as to solve the key problems of enterprise financial synergy. It reveals the problems of the inherent mechanism and model construction of enterprise financial synergistic governance. In addition, it also shows the problems of evaluation and optimization of enterprise financial synergistic governance effects.

\section{The design of synergistic model of enterprise financial management informatization}

\section{The synergistic effect and evaluation of enterprise financial information.}

For an enterprise group, there exists coordination and cooperation of external environment, internal resources and stakeholders, in addition, it also has cooperation among its various 
sub-systems. In general, during the coordination process of all elements of the system and the subsystems, it will produce simple effect which is different from all kinds of the elements and subsystems, and the overall effect of the system is called synergistic effect (SE):

$$
\left\{\begin{array}{l}
S E=F(S)-\sum_{i=1}^{n} F\left(x_{i}\right) \\
S=f\left(x_{1}, . x_{2}, \ldots, x_{n}\right)
\end{array}\right.
$$

Where SE denotes synergistic effect; $F\left(x_{i}\right)$ denotes the effectiveness that $x_{i}$ produces; $F(s)$ denotes the effectiveness that is generated by system $\mathrm{S}$.

Three are three consequences generated by SE: the first one is positive synergistic effect, which means $\mathrm{SE}>0$; the reason why generates positive synergistic effect is that the integration and optimization of internal resources within the system improve the resource utilization efficiency as well as the efficiency of system operation, and save the overall cost of the system. The second one is negative synergistic effect, that is $\mathrm{SE}<0$. In this case, the whole benefits produced by the interaction of various components within the system is less than the sum of the benefits produced by each part of the components. The third one is no synergistic effect, that is $S E=0$. In this case, the whole benefits produced by the interaction of various components within the system is equal to the sum of the benefits produced by each parts of the components.

The evaluation model of net present value shows that financial synergetic effect is composed of four parts, namely "one increase and three reduction”. Let's suppose the increase of operating income is $\Delta \mathrm{R}$, the decrease of the demand is $\Delta \mathrm{C}$, the decrease of tax revenue is $\Delta \mathrm{T}$, and the reduction of enterprise cost is $\Delta \mathrm{C}$, therefore, the incremental cash flow of synergistic effect can be expressed as:

$$
\Delta C F=\Delta \mathrm{R}-\Delta \mathrm{T}-\Delta \mathrm{C}
$$

The net present value of synergistic effect: i means year, and $r$ refers to the discount rate.

$$
N P V=\sum_{1}^{n} \frac{C F_{i}}{(1+r)^{i}}
$$

\section{finance. \\ The construction of three-dimensional synergistic governance model of enterprise group}

In this thesis, the goal of three-dimensional synergistic governance model of enterprise group finance is defined as: the sustained growth of enterprise value. The superiority of the goal is reflected in three parts: firstly, expand the scope of the main goal of financial governance. It expands from the traditional single main goal, that is shareholder, to the key stakeholders, like shareholders, employees, customers and so on, which combines the interests of stakeholders and promote coordination and long-term cooperation among relevant subjects. In this way, it will benefit the long-term development of enterprises; secondly, pay more attention to the long-term development of enterprises. The "long-term" of time is reflected in the "constancy" of the sustainable growth of enterprise value. It requires that the management level of the enterprise should begin with the long-term point of view of the enterprise, make a reasonable localization of enterprise strategy, and put all kinds of financial decisions under the overall framework of enterprise strategy; thirdly, propose the dynamics of value creation. The increase of the value itself is a dynamic concept. No management activity conducted by enterprises can reach the state of perfection. Therefore, continuous efforts and improvements are the goals as well as realm that we pursuit. Furthermore, it is the only road for enterprise to continuously develop and society to make constant progress; fourthly, reflect the sense of social responsibility of enterprise. The goal localization of "the continuous growth of enterprise value" not only reflects the status of enterprises "enterprise broker", but also contains the role of "social being". The performance of the social responsibility contributes to form a benign interaction among enterprises, government and society, which creates a good external environment for the sustainable development of enterprises ( As shown in Fig.1). 


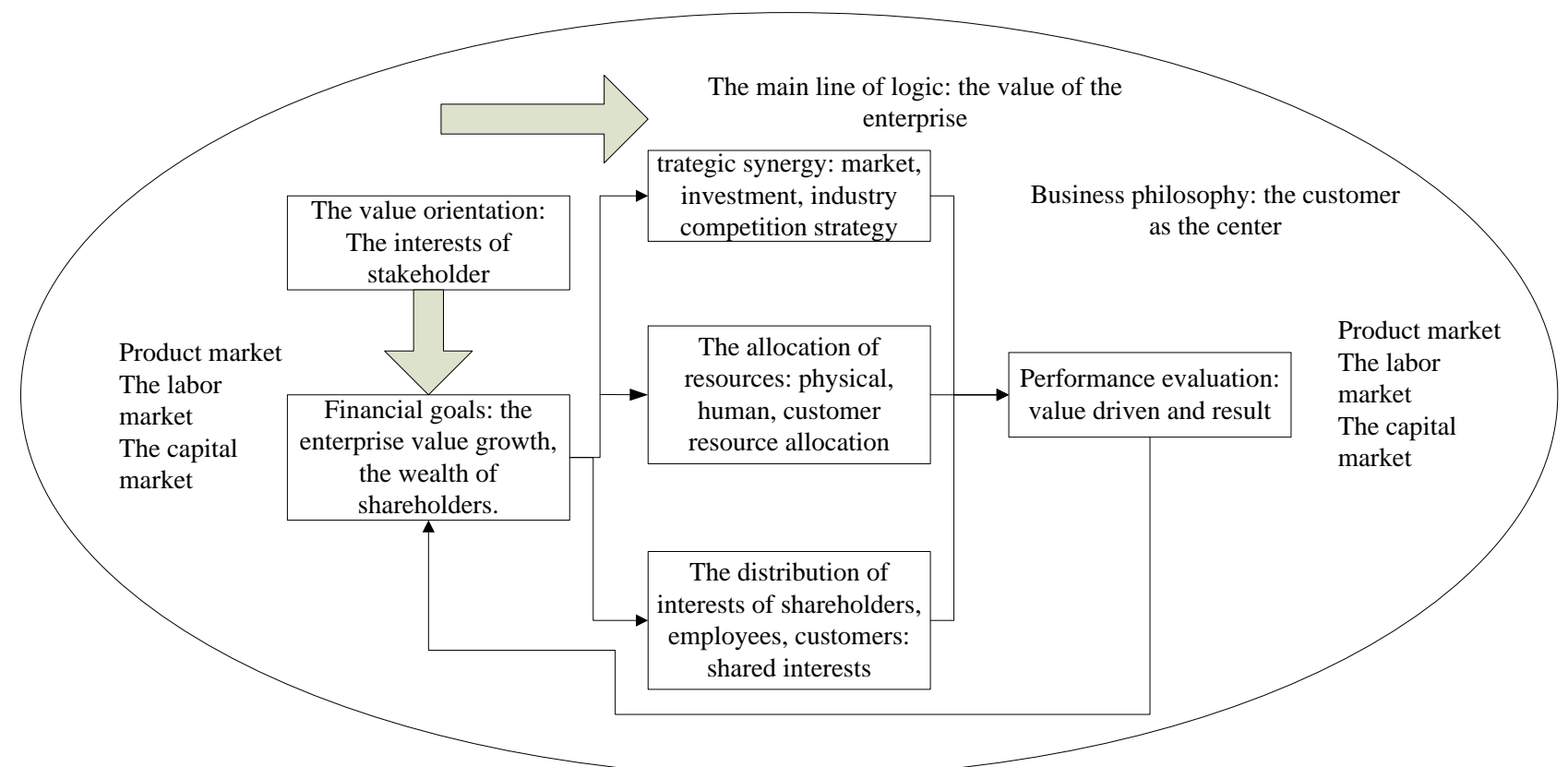

Fig.1. the basic characteristics of synergistic governance model of enterprise group finance

Financial strategy synergy, financial resource synergy and financial interests synergy are three important driving forces of financial synergy of enterprise group. When the three driving forces take effects together, financial synergy of enterprise group will come into full play. However, when one or two driving forces lag behind or play a limited role, the direction of financial synergy may deviate from the intended goal. When financial environmental synergy plays a leading role, group financial synergistic governance, to a certain extent, will not be able to combine the economic values of financial resource synergy and financial interests synergy, for it focuses on improving the robustness of the synergistic system; similarly, When financial interests synergy plays a leading role, the value orientation of the synergistic governance of enterprise group finance will pay more attention to the interests coordination problem of interests stakeholders, which reduces the choice orientation of financial strategy synergy and financial resource synergy.

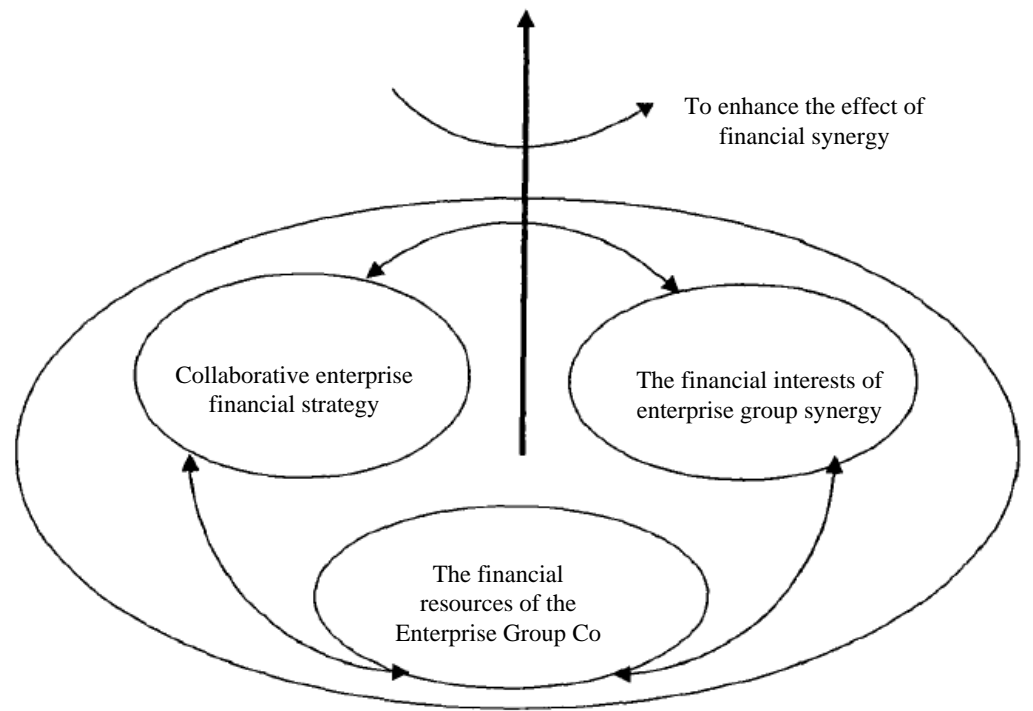

Fig.2. the mechanism of enterprise financial three-dimensional synergy

\section{The evaluation system of three-dimensional synergistic governance effect of enterprise finance.}

According to the influence of synergistic governance of enterprise group finance, we can build the evaluation index system of synergistic effect of enterprise group finance. Its basic framework can be divided into four layers: the goal layer is the highest level of index system, namely, synergistic effect of enterprise group finance. The criteria layer consists of three sub-goals, namely, financial strategy synergy, financial resource synergy and financial interests synergy, which are 
second index. The index layer is the specific index that includes all the sub-goals. The object layer contains the evaluation objects of synergistic effect of this enterprise group finance, which refers to 20 listed Companies. When selecting the evaluation index of enterprise group financial synergy, firstly, we should select the goals whose several aspects can reflect the different characteristics of the research objects and embody the overall properties of the evaluated objects. And then, we have to choose several indexes in each aspect. Next, we will conduct optimization on the representative indexes through using the method of conditional generalized minimum variance. Table1 shows the evaluation indexes of financial strategy synergistic effect, financial resource synergistic effect and financial interests synergistic effect. The evaluation index of financial strategy synergistic effect includes market environment fitness, investment environment fitness and industry competitive profit display degree; The evaluation index of financial resource synergistic effect includes the advantage of resource allocation display degree, the advantage of asset allocation display degree and the advantage of fund allocation display degree; The evaluation index of financial interests synergistic effect includes shareholder satisfaction, employee satisfaction, customer satisfaction as well as supplier satisfaction.

Table1: The evaluation indexes of three-dimensional synergistic governance effect of enterprise group finance

$\begin{array}{llll}\text { The goal layer } & \text { Criterion } & \text { The index layer } & \text { Code }\end{array}$

\begin{tabular}{|c|c|c|c|}
\hline \multirow{10}{*}{$\begin{array}{l}\text { Financial } \\
\text { three-dimensional } \\
\text { synergistic } \\
\text { governance } \\
(\mathrm{X})\end{array}$} & Synergistic & market environment fitness & X11 \\
\hline & governance & investment environment fitness & $\mathrm{X} 12$ \\
\hline & financial strategy $(X 1)$ & industry competitive profit display degree & $\mathrm{X} 13$ \\
\hline & Synergistic & the advantage of resource allocation display degree, & $\mathrm{X} 21$ \\
\hline & governance effect of & the advantage of asset allocation display degree & X22 \\
\hline & $\begin{array}{l}\text { financial } \\
\text { (X2) }\end{array}$ & the advantage of fund allocation display degree & $\mathrm{X} 23$ \\
\hline & $\begin{array}{l}\text { Synergistic } \\
\text { governance effect of }\end{array}$ & shareholder satisfaction & X31 \\
\hline & financial interests & employee satisfaction & X32 \\
\hline & (X3) & customer satisfaction & X33 \\
\hline & & supplier satisfaction & X34 \\
\hline
\end{tabular}

Unascertained measurement refers to the subjective and cognitive uncertainty risen from lacking the evidences of the real state or quantitative relationship of the evaluation objects. In order to measure this kind of uncertainty, the thesis makes a reference of the basic idea of unascertained measurement theory, to establish unascertained measurement model of three-dimensional synergistic governance effect of enterprise group finance. According to the framework of three-dimensional synergistic governance evaluation index of enterprise group finance, the thesis divides the influence factors of the synergy into three categories: governance effect of financial strategy synergy, governance effect of financial resource synergy and governance effect of financial interests synergy. The specific steps of the evaluation (As shown in Fig.3) 


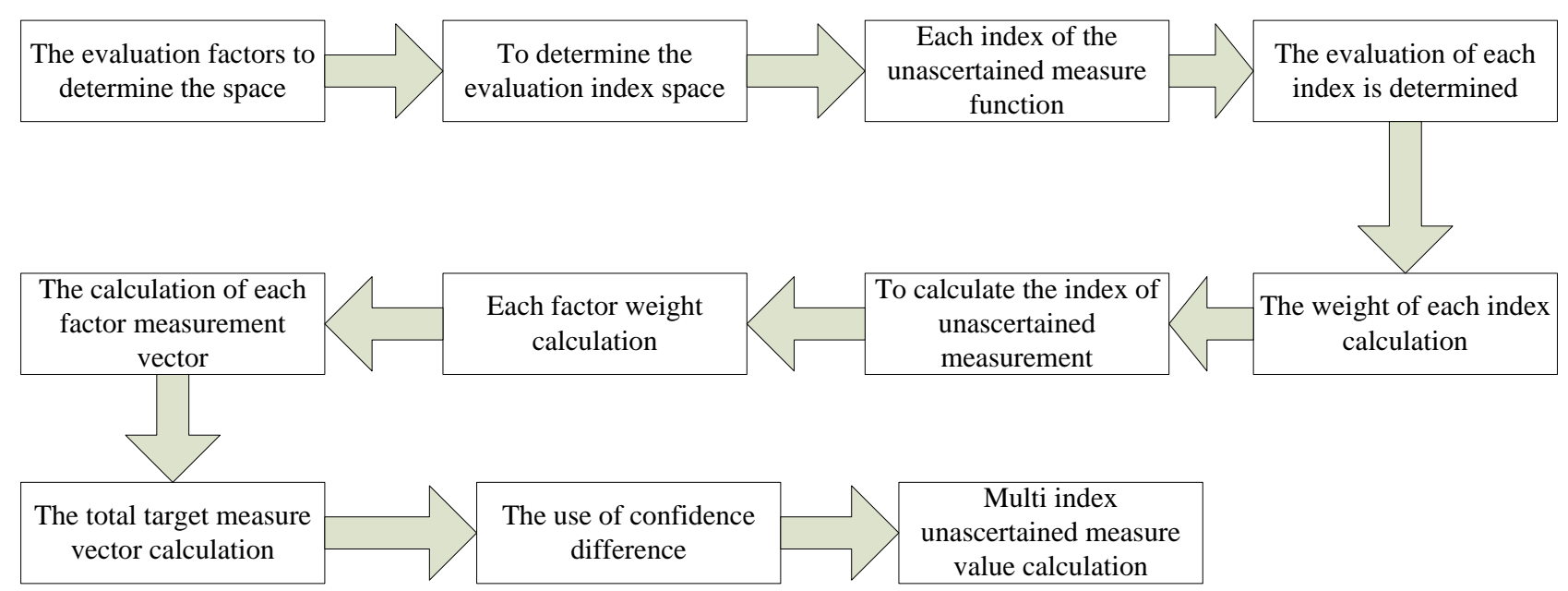

Fig.3. the unascertained measurement process of two-dimensional governance effect of enterprise group finance

The thesis adopts measure function, and the corresponding unascertained measurement functions are as followed:

$$
\begin{gathered}
\mu_{i}(x)=\left\{\begin{array}{l}
\frac{-x}{a_{i+1}-a_{i}}+\frac{a_{i+1}}{a_{i+1}-a_{i}}, a_{i}<x \leq a_{i+1} \\
0, x>a_{i+1}
\end{array}\right. \\
\mu_{i+1}(x)=\left\{\begin{array}{l}
\frac{x}{a_{i+1}-a_{i}}+\frac{a_{i}}{a_{i+1}-a_{i}}, a_{i}<x \leq a_{i+1} \\
0, x \leq a_{i+1}
\end{array}\right.
\end{gathered}
$$

With the application of unascertained measurement matrix, we can obtain the impact of the financial index on enterprise group financial synergy; $\mathrm{K}$ times, through using original formula of information entropy, we can gain the right of all the financial indexes types, m; finally, by combining the single index measurement matrix and the right of index, ?, we can work out the comprehensive measurement of the synergistic degree of enterprise group finance.

The dispersion and concentration degree of entropy model's single index measurement value of synergistic effect evaluation of enterprise finance reflects that the $I_{j}$ index distinguishes the size of category $\mathrm{x}_{\mathrm{i}}$. That is to say, the size $\mathrm{w}_{\mathrm{j}}$ of index $\mathrm{I}_{\mathrm{j}}$ on the classified weight of the sample $\mathrm{x}_{\mathrm{i}}$. However, the dispersion and concentration degree of value $\mathrm{u}_{\mathrm{ijk}}$ can be quantitatively described by information entropy:

$$
\begin{gathered}
H_{i}(j)=\sum_{k=1}^{p} u_{i j k} \log u_{i j k} \\
v_{i}(j)=1+1 / \log p\left(\sum_{k=1}^{p} u_{i j k} \log u_{i j k}\right)
\end{gathered}
$$

Since the evaluation degree is in order, that is $C=\{c 1, c e 2, \ldots, C p\}$, and it also satisfies c1 $>\mathrm{cC} 2>\ldots>\mathrm{cp}$, therefore, we use confidence coefficient for criterion. As for confidence coefficient $\lambda(0<\lambda<1)$, we usually calculate $\lambda=0,7$.

$$
K_{0}=\min \left\{\left[\sum_{i=1}^{k} u_{i l}\right] \geq \lambda, K=1,2, \ldots, k\right\},(1<i<n)
$$

The empirical three-dimensional synergistic governance effect of enterprise finance.

This thesis selects twenty A-share listed company of machinery industry as research samples, and evaluate synergistic effect of enterprise group finance in the perspective of the three dimentions of financial strategy synergy, financial interests synergy and financial interests synergy. Moreover, financial interests synergy also includes two subjective evaluation variables which are satisfaction degree of shareholders and employee, and its data is originated from questionnaire, composed with the subjective evaluation of the shareholders and employees of enterprises. In this thesis, we will 
use Cronbach Alpha Coefficient to conduct a consistency test, so as to judge the reliability of the questionnaire. This thesis will use the questionnaire to collect the data of the satisfaction degree of shareholders and employees, and conduct information processing with the statistical software SPSS 17.0.

The spatial properties of enterprise financial resources synergy is $F, a=\{2,4,6,8,10\}$. $q=6$. 3246. According to the $\mathrm{g}$ values of all sample enterprises, we can rank the synergistic comprehensive effect of the twenty enterprise finances which participate in the evaluation. And the ranking result is shown in Table 2.

Table 2. The comprehensive evaluation of synergistic effect of sample enterprises finances

\begin{tabular}{|c|c|c|c|c|}
\hline Code of enterprise & $\begin{array}{l}\text { Comprehensive measurement } \\
\text { value }\end{array}$ & $\lambda=0.7$ & Composite scores & Rank \\
\hline A9 & $\begin{array}{c}{[0.0490 .0630 .1960 .347} \\
0.345]\end{array}$ & IV & 7.751 & 1 \\
\hline A135 & 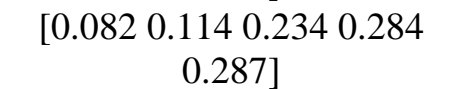 & III & 7.164 & 2 \\
\hline A3 & 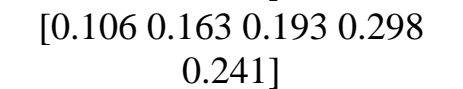 & III & 6.81 & 3 \\
\hline A7 & 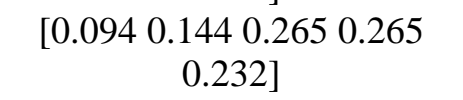 & III & 6.795 & 4 \\
\hline A16 & 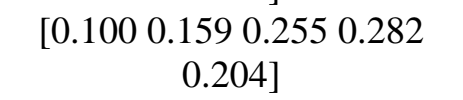 & III & 6.66 & 5 \\
\hline A8 & 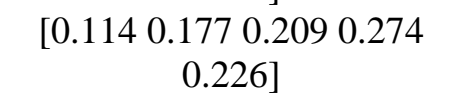 & III & 6.639 & 6 \\
\hline A2 & 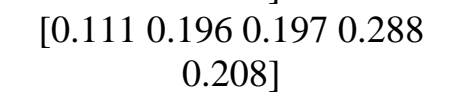 & III & 6.572 & 7 \\
\hline A15 & 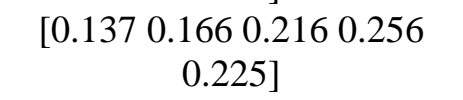 & III & 6.531 & 8 \\
\hline A11 & $\begin{array}{c}{[0.1340 .1380 .26 \mathrm{i} 0.269} \\
0.199]\end{array}$ & III & 6.518 & 9 \\
\hline A1 & 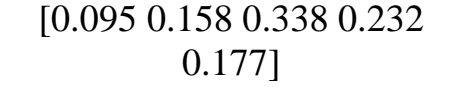 & III & 6.478 & 10 \\
\hline A12 & {$\left[\begin{array}{llllll}0.089 & 0.151 & 0.345 & 0.304 & 0.111\end{array}\right]$} & III & 6.394 & 11 \\
\hline A5 & {$\left[\begin{array}{llllll}0.099 & 0.134 & 0.385 & 0.294 & 0.088\end{array}\right]$} & III & 6.276 & 12 \\
\hline A4 & {$\left[\begin{array}{lllll}0.115 & 0.143 & 0.374 & 0.283 & 0.085\end{array}\right]$} & III & 6.16 & 13 \\
\hline A6 & {$\left[\begin{array}{llllll}0.195 & 0.105 & 0.357 & 0.263 & 0.080\end{array}\right]$} & III & 5.856 & 14 \\
\hline A14 & {$\left[\begin{array}{lllll}0.191 & 0.129 & 0.337 & 0.285 & 0.058\end{array}\right]$} & II & 5.78 & 15 \\
\hline A18 & {$\left[\begin{array}{lllll}0.221 & 0.126 & 0.327 & 0.295 & 0.031\end{array}\right]$} & II & 5.578 & 16 \\
\hline A17 & {$\left[\begin{array}{llllll}0.249 & 0.197 & 0.241 & 0.192 & 0.121\end{array}\right]$} & II & 5.478 & 17 \\
\hline A19 & [ $\left.\begin{array}{lllll}0.258 & 0.1870 .293 & 0.193 & 0.069\end{array}\right]$ & II & 5.256 & 18 \\
\hline A20 & $0.2980 .2170 .2930 .0990 .096]$ & II & 4.944 & 19 \\
\hline A10 & 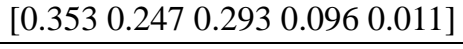 & II & 4.33 & 20 \\
\hline
\end{tabular}

As we can see from Table 2, when the confidence level is 0.7, eight companies are in the middle level and one company is in the poor level of financial synergistic composite scores among the ten enterprise groups which participate in the evaluation. In the perspective of financial synergistic capacity, the overall evaluation is at a level below the average. 


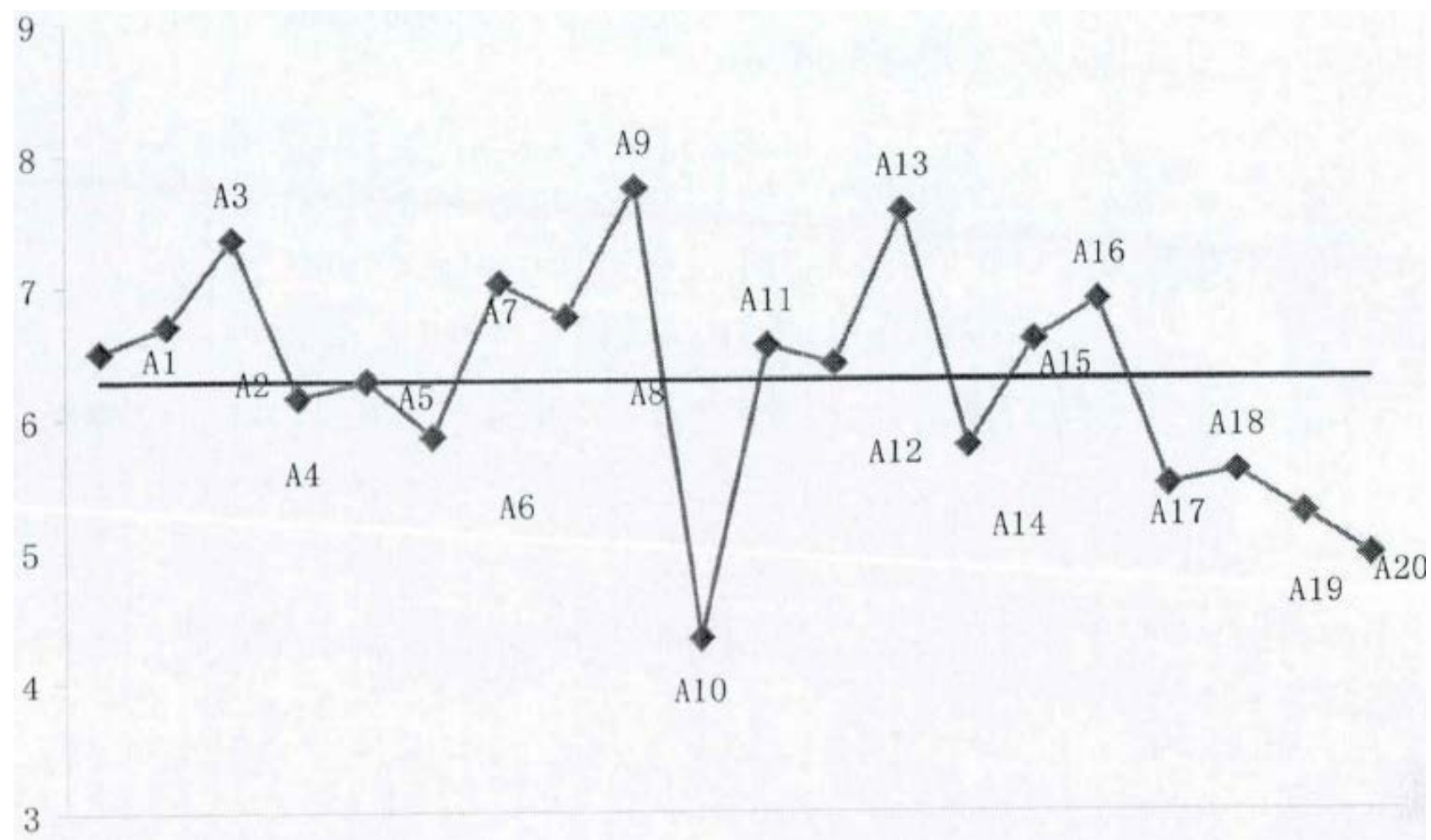

Fig.4. Composite scores distribution of interests synergy of twenty sample enterprise finances

As we can see in Fig.4, in the perspective of composite scores of enterprise financial interests synergy, the average score of the twenty enterprise groups is 6.285. There are eleven enterprises whose scores are above the average, and nine enterprises are lower than the average score. It shows that there exists a great difference of financial interests synergistic capacity of the surveyed enterprises. The reason that leads to these differences mainly comes from different capacities of distinguished enterprises dealing with the interests relationships with shareholders, employees, suppliers and customers. Through comparison, we will analyze the original indexes in the above-mentioned four aspects of A9 enterprise with the highest score and A10 enterprise who has the lowest score. We found that A9 enterprise is significantly higher than A10 enterprise on the aspect of dealing with the interests relationship with employees, suppliers and customers. Therefore, the composite score of A9 was obviously higher than that of A10 enterprise. Even though the composite scores of A9 enterprise is similar to A13 enterprise, there are still great differences of specific capacity. The capacity of A13 enterprise is apparently higher than that of A10 enterprise on the aspect of dealing with the interests relationship with shareholders, but a bit lower on the aspect of dealing with the relationship with customers, employees and suppliers. Therefore, the synergistic effect of enterprise financial interests depends on the capacity of dealing with the synergistic interests relationship with shareholders, employees, customers and suppliers.

\section{Summary}

In order to enhance the ability to adapt to the finance of enterprise group, we conduct strategic integration. The key of enterprise group strategic synergy is not the setting of goals, but the process of implementation. Specifically speaking, we have to enhance the adaptive ability of enterprise group market through resource complementarities, to enhance the adaptive ability of enterprise group investment through scale operation, to enhance the competitive ability of enterprise group market through overall strength, which contributes to realize the strategic goals, and to enhance the resource allocation ability of enterprise group through elements integration. The resource supply of enterprise group is limited, therefore, we should improve industrial competitive ability through the enhance of cash earning capacity, improve asset allocation ability through the increase of the efficiency of capital, improve fund allocation ability through the growth of the turnover of operational fund, improve the coordinate ability of enterprise group interests through relationship 
integration. The relationship among the various links of enterprise group financial governance is essentially a kind of interests relationship. The ultimate goal of synergistic operation is to obtain the maximization of the profits. The benefit balance mechanism, distribution mechanism, sharing mechanism and transfer mechanism which are scientific, fair and mutually beneficial will maintain symmetry in responsibilities, rights and interests, and integrate individual goals with the overall goals on each link, so as to realize the overall maximization of the interests.

\section{References}

[1] H.Xu, K-W.Hipel, D.M.Kilgour. Preference Strength and Uncertainty in the Graph Model for Conflict Resolution for two Decision-Makers. In Proceedings of the IEEE international conference on systems, man and cybernetics, 2008, Vol 1, p2907-2912.

[2] Chen Yongsheng. The Risk Management of Group Enterprise Financial Management Informatization. Accounting Study, 2010, Vol 2, p60-61.

[3] Xia Jinbo. The Comparison and Selection of Centralized Capital Management Mode of Group Company. The Northern Economy, 2010, Vol 1, P 89-90.

[4] Blizer David. Financial innovation and indices: a perspective on financial innovation[J]. Journal of Applied Finanee, 2005, Vol 15, p35-37.

[5] Shi Lei. An Empirical Research on the Living Qualities in Rural Areas under the background of informatization. Nanjing: Nanjing University of Posts and Telecommunications, 2011, P 2-3.

[6] Zheng Lixia. A Brief Analysis of the Advantages of Centralized Accounting Management of Enterprise Group Finance. Finance and Accounting Research, 2010, Vol 12, P 49-50.

[7] Tang Yuqing. The Development and Research of Enterprise Budget Management Theory. China Trade, 2012, Vol 29, P 88-89.

[8] Li Xiaolan. The Discussion of the Comprehensive Budget Management of Enterprise Group. Journal of Shanxi University of Finance and Economics, 2012, Vol 11, P 190-191. 